(C) 1980. The Genetical Society of Great Britain.

\title{
THE DETECTION OF HOMOLOGOUS CHROMOSOME VARIATION IN WHEAT USING BACKCROSS RECIPROCAL MONOSOMIC LINES
}

\author{
J. W. SNAPE and C. N. LAW \\ Plant Breeding Institute, Cambridge, England
}

Received 4.ii.80

\begin{abstract}
SUMMARY
A new method, the backcross reciprocal monosomic method, is described for unambiguously detecting and estimating genetical differences between wheat varieties for single chromosomes. The method involves using a monosomic line(s) for the chromosome(s) under consideration in a two generation crossing programme to produce reciprocal lines which have different homologous chromosomes but identical backcross backgrounds. The original monosomic chromosome can thus be used as a "tester" chromosome to examine homologous chromosome variation in a number of different varieties simultaneously. The method has been used to examine variation for chromosome $5 \mathrm{~A}$ between thirteen varieties of diverse origins. Genetical variation was detected for important agronomic characters and the data for specific chromosomes was used to predict accurately the performance of substitution lines which had previously been developed. The relative merits of the method in comparison with established procedures for specifying varietal differences for single chromosomes are discussed.
\end{abstract}

\section{INTRODUCTION}

Cytogenetical procedures have been developed in bread wheat, Triticum aestivum $(2 n=6 x=42)$ to carry out interspecific and intraspecific transfers of whole chromosomes (Riley and Kimber, 1966; Sears, 1972; Law and Worland, 1973). With respect to intraspecific transfers, single chromosomes can be transferred from one variety to another to form single chromosome substitution lines which consist of twenty pairs of chromosomes of one variety, termed the recipient and a single pair from a second variety, termed the donor. Such transfers can be carried out for each of the twenty one chromosome pairs, providing the appropriate aneuploid stocks, usually monosomics, of the recipient variety are available or can be developed.

Substitution lines have provided powerful tools for genetical analysis of agronomic characters in wheat (Law, 1966, 1968, 1972; Aksel, 1967; Law and Worland, 1973; Snape, Law and Worland, 1975, 1977, 1979). They also have the potential for making direct contributions to breeding programmes where varieties can be improved by the substitution of "useful" variation mediated by single chromosomes from other varieties (Law, Gaines, Johnson and Worland, 1979). Alternatively, novel variants of successful varieties can be produced by single chromosome substitutions to exploit environments not previously open to these varieties (Law, 1980).

An essential prerequisite for the development of substitution lines however, either for use in genetical analysis or in breeding, is the successful identification of appropriate homologous variation between the proposed recipient and donor varieties for the chromosome(s) being studied. It is 
necessary therefore to have methods for identifying the chromosomes mediating varietal differences for quantitative characters and for assessing the homologous chromosome variation available between the recipient and potential donor varieties, in the early generations of a programme. The present paper describes a new procedure for the assessment of chromosome variation in a number of varieties simultaneously. This method, termed the backcross reciprocal monosomic method, has advantages over other methods currently used and compares the variation for a single chromosome from different varieties against that of a single tester chromosome. This method also enables the performance of any proposed substitution line to be predicted. The use of this method is illustrated by examination of homologous variation for chromosome $5 \mathrm{~A}$ from wheat varieties of diverse origins.

\section{BACKCROSS RECIPROCAL MONOSOMIC METHOD}

\section{(i) Crossing procedure}

Two generations of crossing are required to produce the appropriate lines for experimentation. The initial crosses require the choice of an appropriate tester monosomic line $(2 n=41)$ for the chromosome being examined. This monosomic line is preferably of a variety which is intended to be a recipient in a substitution line programme but can be in any suitable variety. In the latter case the intended recipient variety is included in the crossing programme.

\section{(a) Procedure using recipient variety monosomic as tester chromosome}

The crossing procedure involved is shown in fig. 1, using as an example variation for chromosome $5 \mathrm{~A}$. In the first generation, plants monosomic for the tester chromosome are crossed as female to all varieties under test. The progeny of these crosses will segregate for chromosome number, being either monosomic $(2 n=41)$ or disomic $(2 n=42)$ for the chromosome under test, the frequency of each depending on the frequency of nullisomic eggs in

Generation 1: $\quad$ tester monosomic $5 \mathrm{~A} \times$ Variety A, B, C etc.

$$
\begin{array}{l|l}
(2 n=41) & (2 n=42)
\end{array}
$$

Generation 2: tester monosomic 5A $\times \mathrm{F}_{1}$ monosomic hybrid, Variety A $5 \mathrm{~A} \times$ tester monosomic 5A

$$
(2 n=41)
$$

$(2 n=41)$

Generation 3: Backcross monosomic, Variety A 5A

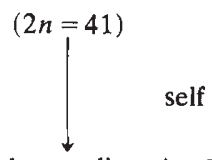

Generation 4: Selfed backcross disomics, Variety A 5A

$$
(2 n=42)
$$

$(2 n=41)$



Backcross monosomic, tester $5 \mathrm{~A}$

self

FIG. 1.-Backcross reciprocal monosomic crossing procedure with recipient monosomic as tester chromosome 
the monosomic. For most chromosomes the frequency of monosomic progeny is expected to be about 75 per cent (Sears, 1954). All monosomic progeny will possess the $5 \mathrm{~A}$ chromosome from the male parent, e.g. variety $\mathrm{A}$, in the monosomic state on an $\mathrm{F}_{1}$ hybrid background for the other twenty chromosome pairs. These monosomic progeny can be identified either cytologically or by phenotype and are then used for a second generation of crossing.

In the second round of crossing the hybrid monosomics are crossed both as male and female to the monosomic tester line. Because of the differential transmission of monosomic chromosomes through the male and female gametes (Sears, loc. cit.), when the $F_{1}$ monosomic hybrid is used as male and the tester monosomic as female, the resulting monosomic progeny will possess, almost exclusively, the variety A chromosome in the monosomic state with backcross segregation for the remaining twenty chromosome pairs. However, when the monosomic hybrid is used as female and the tester monosomic as male the progeny will have similar backgrounds but possess the tester chromosome in the monosomic state.

Thus two sets of monosomic plants can be produced from the crosses involving each variety which differ only in their monosomic chromosome; the backgrounds on average will be the same, namely a backcross between the tester line and the variety. By growing these backcross reciprocal monosomic lines in a properly randomised and replicated experiment, estimates of the genetical differences for agronomic characters between the two sets can be obtained and these relate only to the differences between the homologous monosomic chromosomes. Thus each variety can be tested for variation for the chromosome under test against that of the tester chromosome and all chromosomes ranked accordingly, so that "useful" chromosomes can be identified and then used in a substitution line programme.

The above procedure compares the genetical effects of the chromosomes in the monosomic state. For certain chromosomes however, dosage effects of monosomy may be important and could mask the allelic variation present or, alternatively, exaggerate chromosomal differences. In this case it is necessary to take the backcross reciprocal monosomics a further generation so that disomics, homozygous for the alternative homologues, can be extracted from each monosomic line before effects are evaluated.

The populations of backcross lines produced from each cross may contain disomic plants, formed from euploid female gametes, as well as monosomics, although at an expected frequency of only about 25 per cent. For certain chromosomes, for example 5A, 2A, 2B, 2D these can be readily distinguished from monosomics because of the differences in phenotype caused by monosomy. However for other chromosomes, monosomics are indistinguishable from disomics without cytological screening. The presence of these disomics in the monosomic populations will tend to decrease the detectable chromosomal differences since such plants will be normal backcross plants and, on average, contribute the same to each reciprocal set. However, this effect is unlikely to be large and should only be important if disomics are transmitted differentially through the reciprocal lines.

A further complication which must be considered is the occurrence of nullisomic gametes in the pollen. Such gametes will form nullisomic plants 
when combining with nullisomic eggs or if combining with euploid female gametes, monosomic plants with the "wrong" monosomic chromosome, that is from the female line instead of the male line. However the frequency of such male gametes has been estimated as being less than 2 per cent (Law and Worland, 1973) so this is also unlikely to be a serious source of bias in estimating the effect of the homologous chromosome variation present.

Two cytological phenomena, however, could cause difficulties in producing correct reciprocal lines; first, the presence of translocations involving the chromosome being studied in certain of the varieties; second, univalent shift (Law and Worland, 1973) whereby nullisomic gametes from the female parent are deficient for a chromosome other than that being examined. Both of these phenomena can be detected, however, by cytological testing and incorrect lines removed from the analysis.

If suitable variation is identified in the sample of varieties tested then the development of appropriate substitution lines can be carried out. This can be achieved by using the backcross monosomic plants, having the variety chromosome in the monosomic state as male parents in further rounds of backcrossing to the recipient monosomic, until the recipient background is reconstituted. On selfing the disomic substitution line can be extracted.

\section{(b) Procedure using a variety chromosome as tester chromosome}

Although it is preferable to use an intended recipient monosomic as tester chromosome, any chromosome can in fact be used, by employing a modified crossing procedure as illustrated in fig. 2 . The first generation of crossing is the same as shown in fig. 1 , where all varieties are crossed to any suitable monosomic for the chromosome in question.

\begin{tabular}{c|c} 
Generation 2: & $\begin{array}{c}\mathrm{F}_{1} \text { monosomic hybrid } \\
\text { Variety A 5A } \\
(2 n=41)\end{array}$
\end{tabular}$\quad \begin{gathered}\mathrm{F}_{1} \text { monosomic hybrid } \\
\text { Variety B 5A } \\
(2 n=41)\end{gathered} \quad \begin{gathered}F_{1} \text { monosomic hybrid } \\
\text { Variety A 5A } \\
(2 n=41)\end{gathered}$

Generation 3: "Backcross" monosomics, Variety B 5A $(2 n=41)$

"Backcross" monosomics, Variety A 5 A $(2 n=41)$

FIG. 2.-Backcross reciprocal monosomic procedure with variety A chromosome as tester

In the second generation of crossing, the $F_{1}$ monosomic hybrid for any chosen tester chromosome (here in variety $\mathrm{A}$ ) is crossed reciprocally with all other $\mathrm{F}_{1}$ monosomic hybrids to produce sets of "backcross" reciprocal lines which are segregating for three genomes, namely the chosen starting monosomic, and the two varieties forming the $F_{1}$ monosomic hybrids. However the reciprocal monosomic chromosomes relate only to the two varieties under test and evaluation of the reciprocal sets allows analysis of genetic variation between these variety chromosomes.

This procedure can, in fact, be elaborated further so that comparisons between other or all pairs of chromosomes can be carried out by making the appropriate sets of reciprocal crosses between the sample of $F_{1}$ monosomic hybrids from the first generation of crossing. 


\section{(ii) Genetical expectations}

\section{(a) Means}

The genetical expectations of the means of each backcross reciprocal line for any variety crossed with the tester monosomic can be defined using the terminology of Mather and Jinks (1971). The expectations for the initial monosomic generations and the extracted disomic generation are shown in table 1 , where the subscripts refer to the chromosome effect $(C)$ and the background (B). Here the effects are defined from an origin $m$. $\{d\}_{\mathrm{C}}$ defines the balanced homozygous difference between the variety chromosome and the tester chromosome. This can be a positive or negative effect depending on the direction of the backcross, that is, whether the variety chromosome carries a balance of increasing or decreasing loci relative to the tester chromosome. These expectations also assume that the hemizygous effect of the difference is the same as the disomic difference. However, for situations where dosage effects influence this difference, separate parameters for the monosomic and disomic effect need to be defined.

$\{i\}_{\mathrm{CB}}$ and $\{j\}_{\mathrm{CB}}$ define the balanced sums of the epistatic interactions between the chromosome being tested and the segregating background. Here the sign of $\{i\}_{\mathrm{CB}}$ will again depend on the direction of the backcross, but will differ between reciprocals. The other parameters in table 1 define the effects of the segregating background which are, of course, the normal expectations for a backcross and selfed backcross generation as given by Mather and Jinks (loc. cit.).

The difference between the pair of backcross reciprocal lines will reflect only the homologous chromosome variation and consists of the sum of the homozygous effect and the epistatic interactions, if present, with the segregating background. If differences are obtained between the estimates over the monosomic and disomic generations these will reflect either the dosage difference of the change in the coefficient of $\{j\}_{\mathrm{CB}}$, although in estimation the effects are always confounded. For each variety tested an estimate can be obtained of $\{d\}_{C}$. The relative magnitudes of these values can be used to compare and rank all chromosomes under test.

\section{(b) Variances}

(1) Variance within families. Plants within each backcross reciprocal monosomic line will differ because of the backcross segregation for the twenty background chromosomes. For the crosses involving any one variety however, this segregation will produce the same genetic variance between plants within each reciprocal cross because the hemizygous chromosomes do not contribute to the between plant difference. If differences in the reciprocal within cross variances are apparent, then there is either a differential effect of disomics in the reciprocal samples, or a differential transmission of "switch" monosomics, or interactions which occur between the hemizygous chromosomes and the background.

The crosses involving different varieties may have different backcross variances. The magnitude of the variance will depend on the number, size and direction of gene differences between the background of the tester and the other varieties, and significant heterogeneity of these variances indicates 

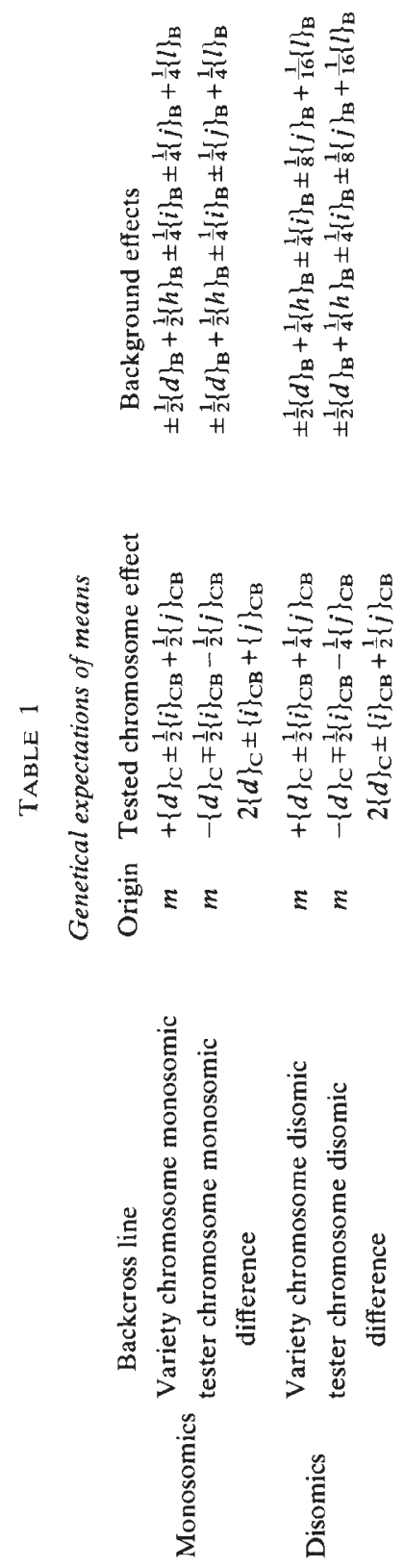
the presence of differences in the backgrounds of the different varieties being used.

(2) Variance of $\{d\}_{C}$ values. The variance of the $n\{d\}_{C}$ values for all $n$ varieties tested estimates the summed effects of the homologous chromosome differences between the variety chromosomes and the tester chromosome. Significance of this item implies that there is genetical variation present for the particular chromosome being examined.

This item becomes more informative when partitioned into two further variances. The first for $1 d f$ tests whether the mean value of $\{d\}_{C}$ is significantly different from zero. This estimates whether the alleles carried by the variety chromosomes act predominantly in one direction relative to the alleles carried by the tester chromosome. If the mean value of $\{d\}_{C}$ is significantly positive then, on average, the varieties being tested carry homologous chromosomes that increase expression of the character over the tester chromosome, and vice versa for a negative value of $\{d\}_{C}$. The second item on partitioning the variance of the $\{d\}_{C}$ values gives a variance for $n-1$ $d f$ which measures the variation of the individual $\{d\}_{C}$ values around their mean. Significance of this item implies that the variety chromosomes are exhibiting genetical variation relative to one another.

\section{EXAMPLE}

\section{(i) Materials and methods}

The example concerns an experiment carried out to examine variation for chromosome $5 \mathrm{~A}$ in twelve varieties of different origins. This chromosome is known to carry genes affecting many important agronomic characters in wheat (Law and Worland, 1973) and the experiment was designed to look at a sample of winter and spring varieties since this chromosome carries a locus determining vernalisation requirement (Law, Worland and Giorgi, 1976).

The 5A monosomic line chosen as the tester variety was of the winter wheat Cappelle-Desprez. This variety has been an important parent in the development of high yielding British winter wheats and the complete set of monosomic lines of this variety were developed at the Plant Breeding Institute. These have also been used extensively as recipients in substitution line development programmes at the PBI where a number of different varieties have been used as donors. The twelve varieties chosen for examination represent firstly, a sample of British winter wheats, Maris Ranger, Hobbit, Sportsman and Villein; secondly a sample of diverse but mainly European winter wheats, Bezostaya I (U.S.S.R.), Mironovskaya 808 (U.S.S.R.), Poros (East Germany), Sava (Yugoslavia) and Atlas 66 (U.S.A.); and thirdly, three spring wheats, Highbury (England), Sicco (Holland) and Chinese Spring (China).

In the first generation of crossing, cytologically checked monosomic $5 \mathrm{~A}$ plants of Cappelle-Desprez were crossed as female with all varieties. In the following generation the monosomic hybrid progeny were cytologically checked and crossed reciprocally with the Cappelle-Desprez monosomic $5 \mathrm{~A}$ line. The backcross reciprocal monosomic progeny so formed were used for the present experiment. 
The experiment comprised a winter sown randomised field experiment where each reciprocal family was represented by five plots. Each plot consisted of a row of eleven plants with a $10 \mathrm{~cm}$ spacing between plants within rows and a $30 \mathrm{~cm}$ spacing between adjacent rows. At maturity, monosomics, which could be readily distinguished from disomics on ear phenotype, were harvested and a range of agronomic characters measured on each individual plant. For the purpose of the present example the results will concentrate mainly on one character, final plant height.

\section{(ii) Results}

The mean performance of each backcross reciprocal family, together with the difference between each pair of reciprocal families, ranked according to magnitude, is shown in table 2. Here, the standard error of the

TABLE 2

Mean performance of backcross reciprocal monosomic families (means of plot means) $C D=$ Cappelle-Desprez

\begin{tabular}{|c|c|c|c|c|c|c|}
\hline Cross & & $\begin{array}{l}\text { Monosomic } \\
\text { chromosome }\end{array}$ & & Mean height $(\mathrm{cm})$ & $\begin{array}{l}\text { Reciprocal } \\
\text { difference }\end{array}$ & $\begin{array}{l}\text { Probability } \\
\text { of difference }\end{array}$ \\
\hline \multirow[t]{2}{*}{ Chinese Spring } & $\times \mathrm{CD}$ & Chinese Spring & $5 \mathrm{~A}$ & $122 \cdot 72$ & $7 \cdot 78$ & $0 \cdot 001$ \\
\hline & & $\mathrm{CD}$ & $5 \mathrm{~A}$ & $114 \cdot 94$ & & \\
\hline \multirow[t]{2}{*}{ Bezostaya I } & $\times \mathrm{CD}$ & Bezostaya & $5 \mathrm{~A}$ & $115 \cdot 15$ & $6 \cdot 10$ & $0 \cdot 01$ \\
\hline & & $\mathrm{CD}$ & $5 \mathrm{~A}$ & $109 \cdot 05$ & & \\
\hline \multirow{2}{*}{$\begin{array}{l}\text { Mironovskaya } \\
808\end{array}$} & $\times \mathrm{CD}$ & Mironovskaya & $5 \mathrm{~A}$ & $123 \cdot 42$ & $5 \cdot 06$ & 0.02 \\
\hline & & $\mathrm{CD}$ & $5 \mathrm{~A}$ & $118 \cdot 36$ & & \\
\hline \multirow[t]{2}{*}{ Sportsman } & $\times \mathrm{CD}$ & Sportsman & $5 \mathrm{~A}$ & $111 \cdot 50$ & $4 \cdot 09$ & 0.07 \\
\hline & & $\mathrm{CD}$ & $5 \mathrm{~A}$ & $107 \cdot 41$ & & \\
\hline \multirow[t]{2}{*}{ Atlas 66} & $\times \mathrm{CD}$ & Atlas 66 & $5 \mathrm{~A}$ & 121.97 & 3.97 & 0.08 \\
\hline & & $\mathrm{CD}$ & $5 \mathrm{~A}$ & $118 \cdot 00$ & & \\
\hline \multirow[t]{2}{*}{ Villein } & $\times \mathrm{CD}$ & Villein & $5 \mathrm{~A}$ & $110 \cdot 60$ & 3.75 & 0.09 \\
\hline & & $\mathrm{CD}$ & $5 \mathrm{~A}$ & $106 \cdot 85$ & & \\
\hline \multirow[t]{2}{*}{ Poros } & $\times \mathrm{CD}$ & Poros & $5 \mathrm{~A}$ & $122 \cdot 38$ & 2.54 & 0.26 \\
\hline & & $\mathrm{CD}$ & $5 \mathrm{~A}$ & $119 \cdot 84$ & & \\
\hline \multirow[t]{2}{*}{ Sicco } & $\times \mathrm{CD}$ & Sicco & $5 \mathrm{~A}$ & $117 \cdot 24$ & $2 \cdot 31$ & $0 \cdot 30$ \\
\hline & & $\mathrm{CD}$ & $5 \mathrm{~A}$ & 114.93 & & \\
\hline \multirow[t]{2}{*}{ Sava } & $\times \mathrm{CD}$ & Sava & $5 \mathrm{~A}$ & $105 \cdot 48$ & $2 \cdot 31$ & $0 \cdot 30$ \\
\hline & & $\mathrm{CD}$ & $5 \mathrm{~A}$ & $103 \cdot 17$ & & \\
\hline \multirow[t]{2}{*}{ Highbury } & $\times \mathrm{CD}$ & Highbury & $5 \mathrm{~A}$ & $111 \cdot 24$ & $1 \cdot 19$ & 0.59 \\
\hline & & $\mathrm{CD}$ & $5 \mathrm{~A}$ & $110 \cdot 05$ & & \\
\hline \multirow[t]{2}{*}{ Hobbit } & $\times \mathrm{CD}$ & Hobbit & $5 \mathrm{~A}$ & $109 \cdot 51$ & 0.78 & 0.73 \\
\hline & & $\mathrm{CD}$ & $5 \mathrm{~A}$ & $108 \cdot 73$ & & \\
\hline \multirow[t]{3}{*}{ M. Ranger } & $\times \mathrm{CD}$ & M. Ranger & $5 \mathrm{~A}$ & $109 \cdot 66$ & $-0 \cdot 95$ & 0.67 \\
\hline & & $\mathrm{CD}$ & $5 \mathrm{~A}$ & $110 \cdot 61$ & & \\
\hline & & & & $\mathrm{SED}=2 \cdot 22$ & & \\
\hline
\end{tabular}

difference between means was calculated using the pooled variances of the plot means within crosses, which were homogeneous over crosses. Clearly there is genetical variation present for loci controlling height on chromosome $5 \mathrm{~A}$, and the relative size of effects would suggest that this chromosome has an important effect on final plant height. The probabilities of difference highlight the differences between the Cappelle-Desprez 5A and the 5A's of the varieties Bezostaya I, Mironovskaya 808 and Chinese 
Spring. However the differences for Sportsman, Atlas 66 and Villein also approach significance. Surprisingly, all of these chromosomes carry alleles which increase height relative to their homologue in Cappelle-Desprez. If these varieties are considered to carry a random sample of $5 \mathrm{~A}$ homologues then the Cappelle-Desprez 5A appears to carry the extreme alleles for "shortness". The 5A chromosomes of the other varieties would appear to be equivalent to the Cappelle-Desprez $5 \mathrm{~A}$ although in the case of Sicco, Sava and Poros slight positive effects are apparent.

TABLE 3

Analysis of variance of reciprocal differences

$\begin{array}{lrc}\quad \text { Item } & \text { df } & \text { MS } \\ \text { Reciprocal differences } & 12 & 395 \cdot 7^{* * *} \\ \text { Mean effect } & 1 & 3157 \cdot 4^{* * *} \\ \text { Variance around mean } & 11 & 144 \cdot 7^{* * *} \\ \text { Pooled variance of plot means } & 96 & 12 \cdot 3 \\ \quad \text { Probability: }{ }^{* *}<0.001 & & \end{array}$

The analysis of variance of the reciprocal differences is shown in table 3 . All items are highly significant. The significance of the variance of the mean effect of all chromosomes indicates that the mean positive deviation of $3.54 \mathrm{~cm}$ is significantly different from zero, confirming the view that Cappelle-Desprez carries alleles whose action is generally to decrease height relative to other $5 \mathrm{~A}$ chromosomes. The significance of variation around this mean confirms that there are significant differences between the other chromosomes. Previous analysis of chromosome 5A (Snape, unpublished) has shown that at least two alleles controlling height are located on this chromosome and it is likely therefore that the gradation in effect found is due to allelic variation at these loci and that Cappelle-Desprez carries the decreasing alleles at all loci relative to the other chromosomes in this sample.

In table 2 , there is significant variation between the backcross families which all have the Cappelle-Desprez $5 \mathrm{~A}$ in the monosomic state. This indicates that there is genetic variation between the background chromosomes for genes controlling height. This was further suggested by the heterogeneity of the within-family variances for the twelve sets of reciprocal families, although no heterogeneity between reciprocals within sets was apparent. However it is difficult to assess the relative contributions of the background chromosomes and the $5 \mathrm{~A}$ chromosomes to variation in plant height because of different genetical expectations for the background effects and the single chromosome effects. Further some of the varieties tested, for example, Hobbit, Sportsman, Villein, Highbury and Sava carry major dwarfing genes. Nevertheless it can be said that the difference of $9 \mathrm{~cm}$ between the extreme homologues is a large effect which would be of significance in a breeding programme.

\section{(iii) Prediction}

The value of assessing homologous chromosome variation can only be realised if the effects estimated using the backcross reciprocal monosomic method predict the performance of the substitution line of a particular 
chromosome. With respect to the present experiment, data are available to test the predictions for two of the chromosomes examined, Bezostaya I $5 \mathrm{~A}$ and Chinese Spring 5A.

The Bezostaya I 5A chromosome has been substituted into CappelleDesprez at the Plant Breeding Institute using the recurrent backcrossing procedures described by Law and Worland (1973). The disomic substitution was extracted after six backcrosses and this line was grown, together with the recipient, Cappelle-Desprez, in a randomised and replicated field experiment adjacent to the corresponding backcross reciprocal monosomic lines described above.

The mean performance of the lines for six agronomic characters is shown in table 4, where probabilities of difference between predicted and observed performance are also presented. No significant differences between the two experiments were observed for any character although for spikelet number a predicted increase of the substitution line did not occur whilst for 50 grain weight no difference was predicted but the substitution line showed a significant increase. These results suggest that for ear emergence time, height, tiller number and grain weight per plant the chromosomal difference is not influenced by hemizygosity or differential interaction with the background. For this chromosome at least, the backcross reciprocal monosomic method is a good predictor of substitution line performance.

The second example concerns the performance of the Chinese Spring $5 \mathrm{~A}$ in comparison with the Cappelle-Desprez 5A. Here, however, the roles of recipient and donor variety are reversed and the data concern the performance of the substitution of the Cappelle-Desprez 5A into Chinese Spring as the recipient. This line was developed at the PBI and had undergone seven backcrosses prior to evaluation. An experiment containing this line and Chinese Spring was grown from a spring sowing and these data, together with the performance of the respective reciprocal backcross monosomic lines for four characters, are shown in table 5.

Significant effects were predicted for plant height and a very close agreement was obtained between observed and predicted performance. For this character the Cappelle-Desprez 5A depresses the height of Chinese Spring almost exactly by the same amount that the Chinese Spring $5 \mathrm{~A}$ increases height in the predominantly Cappelle-Desprez background found in the backcross line. For this character the method not only predicts performance in adjacent experiments but also over seasons. No difference was predicted for ear emergence time, grain weight or 100 grain weight, although for 100 grain weight a significant increase of the substitution line was observed resulting in a significant difference between observed and predicted performance.

\section{Discussion}

The development of backcross reciprocal monosomic lines provides a simple method for detecting homologous chromosome variation and predicting the likely outcome of carrying out a particular chromosome substitution. It can equally be used to define the complete genetical differences between any two varieties by carrying out backcross reciprocal crosses for each of the twenty one chromosome pairs. It thus provides a general chromosome assay procedure in wheat without the necessity of carrying out 


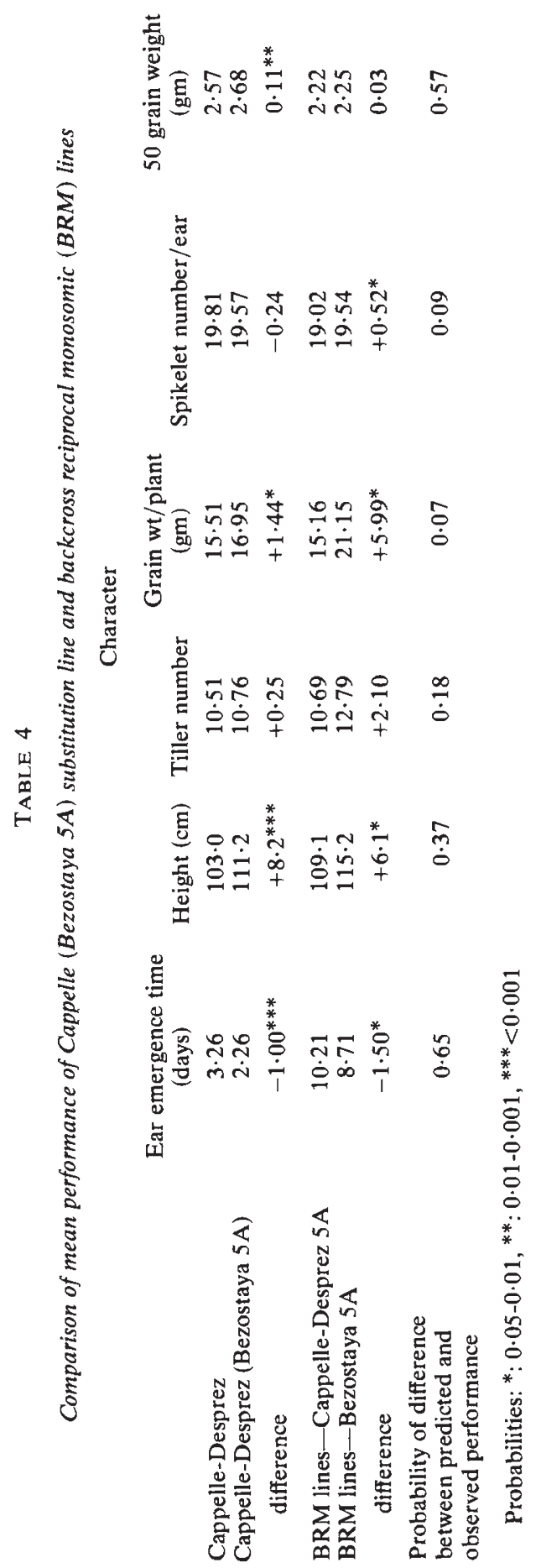




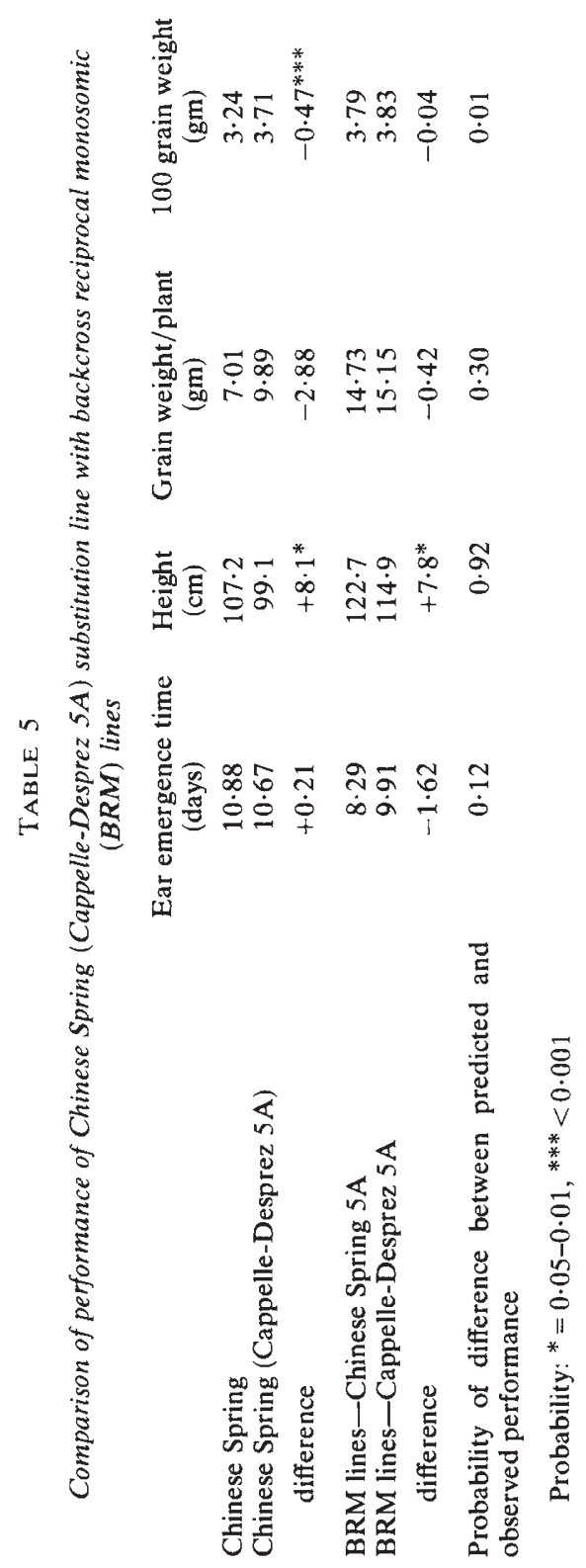


many generations of backcrossing to develop substitution lines before evaluation.

The method is also more generally applicable than other methods of assessing homologous chromosome variation in early generations in wheat. A comparable method is the reciprocal monosomic method (McKewan and Kaltsikes, 1970). However this requires monosomic lines for all the varieties and chromosomes being tested before the necessary crossing procedures can be carried out. This is a criterion which can now be satisfied for many genetical investigations due to the proliferation of monosomic sets in recent years. However for breeding purposes it is necessary to sample many different varieties for variation and it is unlikely that all the necessary monosomics would be available. The reciprocal monosomic method does have the advantage however, that only one generation of crossing, rather than two with the backcross reciprocal method, is required to produce the appropriate lines for evaluation.

Other methods of detecting homologous variation, for example, the $F_{2}$ monosomic method (Larson, 1966; Maystrenko, 1974) and the $F_{3}$ bulk method (McKewan and Kaltsikes, 1970) do not have the reliability of these two reciprocal cross methods because in estimating effects they confound the effect of homologous chromosome variation with chromosome dosage. This makes it difficult to make any prediction of substitution line performance from such methods, or even to ascribe varietal differences to particular chromosomes.

The agreement obtained between predicted and observed substitution line performance from the experiments was very encouraging. Obviously for characters such as final plant height and ear emergence time, which have high heritabilities/repeatabilities, good agreement might have been expected. However, worthwhile predictions were also obtained for plant yield, a character of low heritability. Also, a wide range of variation affecting plant height was uncovered. Not surprisingly, the greatest differences were found for the $5 \mathrm{~A}$ chromosomes of varieties distantly related to Cappelle-Desprez such as the two varieties from the U.S.S.R., Bezostaya I and Mironovskaya 808 , as well as Chinese Spring. The $5 \mathrm{~A}$ effects associated with these varieties are large and would be of significance in any plant breeding programme.

The method therefore provides the means of surveying homologous chromosomal effects from a range of varieties. It allows these effects to be ranked, and by so doing identifies those chromosomes having effects sufficiently large as to be of major effect when substituted into a particular breeding programme. This identification should also make it possible to improve the performance of established varieties in a directed manner using the method of inter-varietal chromosome substitution.

Acknowledgment.-The technical assistance of Mr A. J. Worland and Miss B. B. Parker is gratefully acknowledged.

\section{REFERENCES}

AKSEL, R. 1967. Quantitative genetic analysis of characters in wheat using whole chromosome substitution lines (theoretical considerations). Genetics, 57, 195-211.

LARSON, R. I. 1966. Aneuploid analysis of quantitative characters in wheat. Proceedings of the Second International Wheat Genetics Symposium, Lund 1963, Hereditas Supplement Vol. 2. 345-354. 
LAW, C. N. 1966. Biometrical analysis using chromosome substitutions within a species. In Chromosome Manipulations in Plant Genetics, eds. R. Riley and K. R. Lewis. Suppt. Heredity, 20, 59-85.

LAw, C. N. 1968. Genetic analysis using inter-varietal chromosome substitutions. Proceedings Third International Wheat Genetics Symposium Canberra, 331-342.

LAW, C. N. 1972. The analysis of inter-varietal chromosome substitutions in wheat and their first generation hybrids. Heredity, 28, 169-179.

LAW, C. N. 1980. Developmental studies in wheat using whole chromosome substitution lines. Proceedings 14th Intn. Congress of Genetics, Moscow.

LAW, C. N., AND WORLAND, A. J. 1973. Aneuploidy in wheat and its uses in genetic analysis. Annual Report Plant Breeding Institute 1972, 25-65.

LAW, C. N., WORLAND, A. J., AND GIORGI, B. 1976. The genetic control of ear emergence time by chromosomes $5 \mathrm{~A}$ and $5 \mathrm{D}$ of wheat. Heredity, 36, 49-58.

LAW, C. N., GAINES, R. C., JOHNSON, R., AND WORLAND, A. J. 1979. The application of aneuploid techniques to a study of stripe rust resistance in wheat. Proceedings Fifth International Wheat Genetics Symposium, New Delhi, 427-436.

MAYSTRENKO, O. I. 1974. Identification of chromosomes carrying genes $V r n 1$ and $V r n 3$ inhibiting winter habit in wheat. European Wheat aneuploid co-operative Newsletter, 4, 49-62.

McKEWAN, J. M., AND KALTSIKES, P. J. 1970. Early generation testing as a means of predicting the value of specific chromosome substitutions into common wheat. Can. J. Genet. Cytol, 12, 711-723.

MATHER, J., AND JINKS, J. L. 1971. Biometrical Genetics, Chapman and Hall Ltd., London. RILEY, R., AND KIMBER, G. 1966. The transfer of alien genetic variation to wheat. Annual Report Plant Breeding Institute, 1964-65, 6-36.

SEARS, E. R. 1954. The aneuploids of common wheat. Missouri Agricultural Experiment Station, Research Bulletin, 572, 1-58.

SEARS, E. R. 1972. Chromosome engineering in wheat. Stadler Symposia Vol., 4, 23-38.

SNAPE, J. W., LAW, C. N., AND WORLAND, A. J. 1975. A method for the detection of epistasis in chromosome substitution lines of hexaploid wheat. Heredity, 34, 297-303.

SNAPE, J. W., LAW, C. N., AND WORLAND, A. J. 1977. Whole chromosome analysis of height in wheat. Heredity, 38, 25-36.

SNAPE, J. W., LAW, C. N., YOUNG, C.F., AND WORLAND, A. J. 1979. Genetical analysis of chromosome substitution lines of bread wheat using second generation hybrids. Heredity, $42,247-258$. 